\title{
Article
}

\section{Challenges and opportunities: the role of the district nurse in influencing practice education}

\author{
Ashworth, Lisa \\ Available at http://clok.uclan.ac.uk/34435/ \\ Ashworth, Lisa (2020) Challenges and opportunities: the role of the district \\ nurse in influencing practice education. British Journal of Community Nursing, \\ 25 (8). ISSN 1462-4753
}

It is advisable to refer to the publisher's version if you intend to cite from the work.

For more information about UCLan's research in this area go to http://www.uclan.ac.uk/researchgroups/ and search for < name of research Group>.

For information about Research generally at UCLan please go to http://www.uclan.ac.uk/research/

All outputs in CLoK are protected by Intellectual Property Rights law, including Copyright law. Copyright, IPR and Moral Rights for the works on this site are retained by the individual authors and/or other copyright owners. Terms and conditions for use of this material are defined in the policies page.

\section{CLoK}

Central Lancashire online Knowledge www.clok.uclan.ac.uk

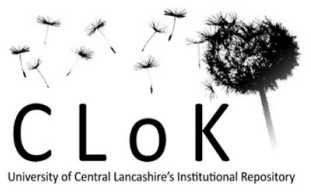


Challenges and opportunities: The role of the District Nurse influencing practice education.

Key words: Community Specialist Practice District Nurse Education

District Nurse Apprenticeship Quality Assurance Standards Contemporary Curriculum

\section{ABSTRACT}

The responsibility of the District Nurse [DN], alongside complex case management and leadership is to ensure Specialist Practitioner Qualification District Nurse [SPQDN] education continues to create practitioners delivering quality evidence-based care. DN leadership and its importance has come to the fore during the Covid-19 crisis where hospital discharges increased rapidly to make way for highly complex Covid admissions (HM Government, 2020). This paper will examine the importance of the SPQDN qualification, exploring the role of the DN within practice education. Continuation of the vital DN qualification will ensure numbers of qualified DNs increase, ultimately protecting community capacity. With a move towards an apprenticeship model to achieve the SPQDN, DNs must engage and influence curriculum development to confirm courses deliver requirements of the current workplace, commissioners, and NHS Long Term Plan (National Health Service [NHS] England, 2019). Expectations of the DN role within practice education have undergone a revision, moving away from the Practice Teacher standards to the new NMC Standards for Student Support and Assessment [SSSA]. This poses new challenges in DN education in practice. Implications of this transition threatens to de-value the quality of the assessment process by removing the high standards of preparation previously demanded; ultimately being a risk to the provision of quality of practice education which has previously existed. 


\section{What are the current challenges in DN practice?}

The qualified DN is vital in meeting current challenges in contemporary community practice which has become more pressurised during the current Covid-19 crisis. The need to provide high quality care with consideration of commissioning requirements has been challenging with the rapid rise in caseload numbers. According to Alderwick et al. (2016), commissioning requirements including sustainability and transformation plans [STPs] were introduced by NHS England in response to challenges faced in Health and Social Care; highlighted in the publication NHS five year forward view (DHSC, 2014; NHS England, 2016). This has since resulted in the development of the NHS Long Term Plan (NHS England, 2019) which sets out targets in achieving a new service model joining up care in the most appropriate setting with community care being a main focal point. This focus of transfer of care to the community setting has been highlighted as essential during the current pandemic. NHS organisations in differing geographical fractions of the UK have been asked to work in partnership with many Clinical Commissioning Groups [CCG] merging to counter health and social care concerns, examining service provision required to meet the needs of local populations to attain the targets set by the NHS Long Term Plan (DHSC, 2014; NHS England, 2019; NHS England, 2020). Nursing is a passionate, enterprising profession which must respond to fluctuating pressures within health care and rise to the challenges set, (Pringle 2009). The Covid-19 crisis has set unprecedented challenges with DNs needing to find new ways of working to meet the increase in demand. Within the role of the $\mathrm{DN}$, there is a requirement to work innovatively with limited resources and to safeguard effective delivery of services from DNs which are both high quality and cost effective (DHSC, 2010; DHSC, 2013; QNI, 2015; QNI 2017; QNI, 2019). To meet challenges set by both Covid-19 and future service provision, SPQDNs require a high level of education both in university and practice. 


\section{The role of the DN in influencing future education and practice.}

The need to create a workforce which can deliver high quality community care, meeting commissioning requirements as well as address the shortage of qualified DNs has already traversed with calls for transforming nursing education into the new DN Apprenticeship route (Benner et al., 2010; Henderson and Hassmiller, 2007; IATE, 2020). A challenge DNs encounter is how to navigate complex learning environments whilst managing an increasing scale of nurse practice despite working within difficult financial constraints and challenges posed by the current Covid-19 crisis (DHSC, 2011; Pringle, 2009; QNI, 2019; Seib et al., 2011). These challenges not only affect specialist practice but also the progression of nurse education, therefore curriculum development is essential (Benner et al., 2010; NMC, 2018; QNI 2015; Seib et al., 2011). In relation to the SPQDN educational programme and development of the DN Apprenticeship, DNs must contribute to the provision of relevant, receptive, evidence-based training and education (Giddens and Brady, 2007; IATE, 2020; Kantar and Alexander, 2012; QNI, 2015; Seib et al., 2011; Van de Mortel and Bird, 2010). Previously, educational programmes have been criticised for being too grounded in tacit knowledge (Giddens and Brady, 2007; Kantar and Alexander, 2012; Tanner, 2009). An example of this within current academia within the SPQDN qualification is an implied understanding that current SPQDN students will become future leaders based on attaining the current standards outlined by the NMC (NMC, 2001). However, as discussed, as well as reaching NMC standards, there must also be consideration of the requirements of the future workforce (Addicott et al., 2015; Benner et al., 2010; Royal College of Nursing [RCN], 2013). DNs are well placed to influence curriculum development to deliver these demands in terms of contributing to the development of the new DN Apprenticeship (IATE, 2019; NMC, 2018). One such requirement highlighted in practice is evolving advanced practice skills unique to the DN role in both clinical diagnostics and advanced prescribing. These skills are currently not a prerequisite to achieve the SPQDN qualification, however attaining these within the new DN Apprenticeship would strengthen the qualification to meet current needs of the DN caseload, 
the challenges highlighted through the current pandemic as well as achievements of NHS Long Term Plan (DHSC, 2013; DHSC, 2014; IATE, 2020; NHS England, 2019; QNI, 2019). Developing nursing skills such as prescribing and clinical diagnostics in the community was discussed widely within the Shape of Caring Review produced by HEE (2015) aiming to guarantee high class nursing education to ensure services delivering high quality care. The role of the DN is to contribute to such role development and within practice, is in the strongest position to provide robust leadership in delivering these new services (Carr and Gidman, 2012; NMC, 2001; QNI, 2019; Yuki, 2010).

\section{Current SPQDN Role in practice education}

The challenges posed during the current Covid-19 crisis has highlighted now more than ever the role played by SPQDN educators in practice, teaching and educating future SPQDN leaders to provide excellent responsive community care. The role of the DN educator which now incorporates two professionals, Practice Supervisors and Practice Assessors, both supporting SPQDN students in practice should be to effectively work across both academic and practice settings to ensure quality within the SPQDN education (NMC, 2018). In line with NMC, QNI, and future DN Apprenticeship Standards, DN educators must work towards creating professional status as a qualified SPQDN and educators teaching future DN team leaders (IATE; 2020; QNI, 2015; QNI, 2019). Johnson et al. (2012) maintain nurse education remains crucial to preserving professional prominence. At a time when funding and training courses to become DNs have been under threat of reduction, it is vital in clinical practice the importance of supporting learning in role development is strongly demonstrated to ensure NHS Trusts and third sector parties recognise the role as vital and utilise their apprenticeship levy. Providing an effective learning environment for SPQDN students plays a pivotal role in creating professional identity for DNs fulfilling their responsibility in contributing to academia and provision of empirical learning in practice (Johnson et al., 2012; NMC, 2018a; QNI, 2019). 
According to Adams (2013), there is a close link between structures in place in the practice environment and how individual DNs define themselves. The workplace setting inevitably moulds the individual, but equally the individual also has the capacity to influence work practice and organisation (Adams, 2013). This would suggest DNs within the clinical arena can influence how their role is operationalised at a strategic level and how, in clinical practice they have the ability to influence and shape the future SPQDN workforce; something which is crucial during current health crisis (Adams, 2013; Kleebauer, 2016; QNI, 2019).

To ensure quality of the SPQDN programme in both the current traditional route and future DN Apprenticeships, assurance must be reached that within the learning environment future SPQDN students themselves will become educators to continue the cycle and production of quality (QNI, 2015; RCN, 2013). The NMC Standards for Student Support and Assessment [SSSA] moves away from SPQDN Practice Teacher qualification to a model of Practice Supervisor and Practice Assessor in practice; a change for DN practice education (NMC, 2018). Advantages to the SSSA include the Practice Supervisor role being widened and the recognition of the contribution of a host of multi-professionals in DN education (NMC 2018). There is also the potential minimising of risk of toxic mentorship by splitting the Supervisor and Assessor roles (Swazey and Anderson, 1996). There are concerns in the potential dilution of the quality of the Practice Assessor role in DN education. The Practice Teacher qualification required the undertaking of two post graduate modules and is replaced by a non-credit workshop to prepare a Practice Assessor with no face to face contact or assessment required. Teaching and assessing is a profession with skills and knowledge above that which is currently taught in nurse education. This change threatens to de-value the quality of the assessment process by removing the high standards of preparation previously demanded. It will be a challenge both for those preparing Practice Assessors and those undertaking the Practice Assessor roles to maintain quality in the DN assessment practice process. With the dissolution of the Practice Teacher role it is vital that a level of education in teaching future District Nurses 
in practice exists. It is widely felt by academics and educators within the clinical arena that consideration should be given to the development of an academic teaching qualification for those assessing specialist practitioners above that of the SSSA standards, which only provide minimal education with some areas developing online training to achieve these roles.

\section{Current picture in SPQDN education}

The current SPQDN degree or post graduate diploma enables the entrant the title DN when completed (Green, 2016; Nursing \& Midwifery Council [NMC], 2001). On completion of the course, the SPQDN student must have attained the official standards for DN education and practice, formulated by the United Kingdom Central Council [UKCC] in 1994 and reprinted by the NMC in 2001 (NMC, 2001; UKCC, 1994). These standards currently form the basis of SPQDN education in both university and practice leading to a recordable qualification (Green, 2016; NMC, 2001). The NMC standards are built upon the SPQDN exercising higher levels of judgement in clinical care, including assessment, planning, implementation and evaluation of specialist nursing care alongside effective leadership in the role as a SPQDN (Department of Health and Social Care [DHSC], 2013; NMC, 2001). The role of the DN in practice is to teach and assess as competent those undertaking the SPQDN to ensure that the highest standards are met in clinical practice for students who wish to become qualified DNs (Hollinshead and Stirling, 2014; NMC, 2001; Sayer, 2011). One essential role within District Nursing is to ensure education based on these standards maintains congruence with contemporary best practice, however disappointingly the DN qualification remains underpinned by standards and definitions written more than 20 years ago (Dickson et al. 2011). In response to this, the Queen's Nursing Institute [QNI] and Queen's Nursing Institute Scotland [QNIS] worked collaboratively with senior groups from education, commissioners, voluntary sector, the NMC, and UK national governments to introduce voluntary standards in 2015 (Oldman, 2016; QNI, 2015). The intention of the QNI/QNIS Voluntary Standards for DN Education and Practice is 
to improve, not supersede, the existing NMC standards and endeavour to enhance educational courses for current and future DN practice; aiming to provide holistic care, deliver complex caseload management and prevent avoidable hospital admissions (Oldman, 2016; QNI, 2015). Education also forms one of the four pillars within the QNI standards (QNI, 2015). QNI standards remain voluntary with some believing this may produce inequity in interpretation and implementation in both practice and formalised DN education, leading to variations in benchmarks to which future DNs reach on qualification (Montt, 2011). With the introduction of the new DN Apprenticeship which has been sanctioned, new knowledge, skills, behaviours and duties will form unity across education provision to ensure the standards to which modern day DNs should be working are attained; better reflecting current practice (Institute for Apprenticeships and Technical Education [IATE], 2020). With many Higher Educational Institutes [HEI] hoping to commence courses by September 2021, students will then utilise the Apprenticeship route to achieve the SPQDN once the traditional route becomes no longer viable for Trusts in England due to continuing threats to funding across varying sectors. The DN Apprenticeship course will be mapped against the current NMC competencies to enable the qualification to be recorded on the register however these still remain dated. There is hope that new standards will be written by 2022 but in current Covid-19 health crisis, educators are concerned with how and when the new standards will be implemented.

\section{Investment required}

Alongside changes in curriculum and education provision and concerns around implementation of new NMC standards, there are apprehensions around failure of commissioners to acknowledge the qualification as a requirement in future community nursing (Longstaff, 2013). The QNI has campaigned for improved investment in SPQDN education, with the fundamental aim to reverse the decline in entrant numbers of new DN students and the number of courses being offered (Green, 2016; Oldman, 2017; QNI, 2015; QNI, 2019). 
Ultimately in the clinical arena, with funding being provided through the apprenticeship levy; working towards the new DN Apprenticeship Standards, QNI standards with achievement of the NMC standards will be the only way to provide quality assurance for those who are given the job title of DN, providing benchmarks for standards of practice to which all SPQDNs should be working towards (DHSC, 2014; Green, 2016; IATE; 2020; NMC, 2001; QNI, 2015; QNI, 2019). As DN educators in clinical practice, instilling the QNI standards in the design and implementation of teaching strategies, as well as the NMC standards alongside the future knowledge skills and behaviours of the DN Apprenticeship standards, serves to provide the highest outcomes in supporting learning across both practice and academia (DH, 2014; IATE, 2020; NMC, 2001; NMC, 2018; QNI, 2015).

\section{The role of the DN in influencing curriculum.}

With current shortages of DNs across the country ultimately affecting the quality of care provided, it is vital DNs contribute (Maybin et al., 2016; QNI, 2015; QNI, 2019). In order to ensure such contribution, in the clinical arena DNs must continue to engage in links with the HEI to influence curriculum development to ensure new proposed courses delivers requirements of the current workplace (NMC, 2017; NMC, 2018). In clinical practice, this is currently being achieved through strategy meetings which must form part of any Apprenticeship (IATE, 2020). Maintaining strong connections through continuation of practice/educator forums held throughout the year at most universities are aimed at providing a platform for such links to be formed. Sarah Marquis, SPQDN Modern Matron at Lancashire and South Cumbria NHS Foundation Trust says

\footnotetext{
" the complexity and skill required to be an effective SPQDN can only be achieved through a robust partnership with our University colleagues. As a SPQDN and qualified practice teacher, it is crucial that we understand the curriculum and the standards expected so that we can help mould our future DN leaders. There is nothing more rewarding than seeing a SPQDN student grow in confidence and bring their theoretical knowledge to life in the clinical environment"
} 
When discussing influencing curriculum development, it is vital DNs understand the curriculum and how to embolden the practice element to the adult learner within an effective learning environment (NMC, 2018). Adult learners require influence over personal learning and in integrating knowledge from theory into practice which is said to expand through the application of adult learning (Knowles et al., 2011; Ruesseler and Obertacke, 2011). In clinical practice, knowledge of adult learning theory within curriculum delivery of bridging the theory practice gap supports the use of self-directed learning (Carnell, 2007; Curran, 2014; Jokinen and Mikkonen, 2013; Ruesseler and Obertacke, 2011). Learner-centred teaching and curriculum design is said to promote theory-practice integration into the workplace creating a future quality workforce (Curran, 2014; Drewitt, 2008; Jokinen and Mikkonen, 2013; Knowles et al., 2011; Speicher and Kehrhahn, 2009). The DN role is therefore to design, implement and evaluate learning strategies and learning environment across both practice and academia which ensures the creation of this quality workforce (NMC, 2018; QNI; 2019). This will have the ultimate aim of increasing SPQDN numbers, developing the workforce to meet challenges and demands highlighted throughout this paper.

\section{Conclusion}

The NMC post registration standards review has arrived at a critical time within community practice. The need to strengthen both the workforce and the qualification is highlighted as being essential in meeting the current demands in community care. DNs have been at the forefront of providing high quality nursing care during the Covid-19 crisis and have responded with emphatic professionalism to the sudden increase in caseload demands caused by rapid discharges from acute care, allowing hospitals to deal with Covid-19 admissions. The world of healthcare has dramatically changed, and District Nursing must be contemporaneous to keep 
up. With CCG's requiring leadership with delivering the NHS Long Term Plan, DN education must evolve to meet these needs.

The role of the DN in practice is to educate, teach and assess as competent those undertaking the SPQDN course, supporting learning across practice and academia to ensure the highest standards are met (Alderwick et al., 2016; Hollinshead and Stirling, 2014; NHS England, 2019; NMC, 2001; QNI, 2019). This is to safeguard overall quality of the SPQDN role ensuring the qualification continues to be a requirement of the DN job title (Adams, 2013; Alderwick et al., 2016; QNI, 2015; QNI 2019). Changes through commissioning within the DN workforce make the dual clinical and educational role increasingly more complex, causing challenges to facilitation and assessment of students in practice and in creating an effective learning environment (Carr and Gidman, 2012; Haydock et al., 2011; Kenyon and Peckover, 2008). There is therefore a need in clinical practice to provide quality assurance on a strategic level to ensure those commissioning the service can see the value in the continuance of the SPQDN qualification to safeguard provision of the highest standards within the practice (QNI, 2015; QNI 2017; QNI, 2019). There is therefore the need to ensure NHS Trusts continue to fund future education via the Apprenticeship levy.

DNs must engage in links with the HEI to influence curriculum development to confirm the future DN Apprenticeship delivers requirements of the current workplace. In relation to DN education, it is essential DNs in practice contribute to provide relevant, contemporary education such as advanced diagnostics and prescribing to ensure the highest standards in patient care are met within the practice learning environment (Addicott et al., 2015; QNI, 2015; QNI, 2017). There is a requirement in clinical practice to safeguard the quality of SPQDN education with the need to ensure those providing teaching and learning in practice have the necessary qualifications to be able to provide this to the highest standards. To maintain this 
level of quality it is suggested DNs assessing SPQDN students should be educated to a higher level than that provided by the SSSA, through documented educational teaching knowledge and skills.

\section{KEY POINTS}

- Continuation of the DN qualification is vital to benchmark standards of practice.

- DNs have the ability to influence and shape future SPQDN workforce through documented teaching and learning in practice.

- DNs should engage with curriculum development to ensure SPQDN education, including DN Apprenticeships, meet the requirements of commissioners, practice population and achievement of the Long Term Plan. DNs are is in the strongest position to provide robust leadership in delivering these services.

- DNs hold a responsibility to continue quality education of future SPQDN students. Consideration to the level of education required to teach and educate specialist practitioners in the practice environment needs to be discussed.

\section{CPD REFLECTIVE QUESTIONS}

- What is your role as a DN in educating SPQDN students within the practice environment?

- What forum can you utilise to engage with your local HEI to ensure courses developed meet the requirements of current DN practice? 
- How can you work with commissioners and NHS Trust leads to demonstrate quality of the DN role and the continuance of the qualification as a requirement of the title/role?

- What level of education do your current DN educators hold and how can this be protected to maintain quality in the future?

\section{$\underline{\text { References }}$}

Adams K. Practice teaching: professional identity and role recognition. Community Practitioner. 2013; 10, 20-23. ISSN: 14622815

Addicott R, Maguire D, Honeyman M, Jabbal J. Workforce planning in the NHS. The King's Fund: London: 2015.

Alderwick H, Dunn P, McKenna H, Walsh N, Ham H. Sustainability and transformation plans in the NHS: How are they being developed in practice? The Kings Fund: London: 2016.

Benner P, Sutphen M, Leonard V, Day L. Educating nurses: A call for radical transformation. 2010. Jossey-Bass: San Francisco, CA: 2010.

Carnell E. Conceptions of effective teaching in higher education: Extending the boundaries. Teaching in Higher Education. 2007; 12(1), 25-40. doi: 10.1080/13562510601102081.

Carr D, Gidman J. Juggling the dual role of practitioner and educator: Practice teachers' perceptions. Community Practitioner. 2012; 85(2), 23-26. ISSN: 14622815

Curran, MK. Examination of the teaching styles of nursing professional development specialists, part I: Best practices in adult learning theory, curriculum development and 
knowledge transfer. The Journal of Continuing Education in Nursing. 2014; 45(5), 233-240. doi: 10.3928/00220124-20140417-04.

Department of Health and Social Care. Liberating the NHS: Equity and excellence. 2010. https://www.gov.uk/government/publications/liberating-the-nhs-white-paper (accessed 20 May 2020)

Department of Health and Social Care. Care in local communities: A new vision and model for district nursing. 2013. https://www.gov.uk/government/publications/vision-for-districtnursing (accessed 27 May 2020)

Department of Health and Social Care. Five year forward view. 2014.

https://www.england.nhs.uk/wp-content/uploads/2014/10/5yfv-web.pdf (accessed 30 May 2020)

Dickson $\mathrm{C}$, Gough $\mathrm{H}$, Bain $\mathrm{H}$. Meeting the policy agenda, part 1: The role of the modern district nurse. British Journal of Community Nursing. 2011; 16(10), 495-500. doi: 10.12968/bjcn.2011.16.10.495.

Giddens JF, Brady DP. Rescuing nursing education from content saturation: The case for a concept-based curriculum. Journal of Nursing Education. 2007; 46, 65-71. doi: 10.3928/01484834-20070201-05.

Green, J. Enhancing assertiveness in district nurse specialist practice. British Journal of Community Nursing. 2016; 21(8), 400-403. doi: 10.12968/bjcn.2016.21.8.400.

Health Education England. Raising the bar, shape of caring: A review of the future education and training of registered nurses and care assistants. 2015. https://www.hee.nhs.uk/ourwork/developing-our-workforce/.../shape-caring-review (accessed 23 May 2020)

Henderson TM, Hassmiller SB. Hospitals and philanthropy as partners in funding nursing education. Nursing Economics. 2007; 25, 95-100. ISSN: 07461739 
Hollinshead J, Stirling L. A conceptual curriculum framework designed to ensure quality student health visitor training in practice. Community Practitioner. 2014; 87(7), 22-25. ISSN: 14622815

HM Government. COVID-19 Hospital Discharge Service Requirements. 2020. https://www.gov.uk/government/publications/coronavirus-covid-19-hospital-dischargeservice-requirements (accessed 30 May 2020)

Institute for Apprenticeships and Technical Education. District Nurse Apprenticeship. 2020. https://www.instituteforapprenticeships.org/apprenticeship-standards/district-nurse/ (accessed 30 May 2020)

Johnson M, Cowin LS, Wilson I, Young H. Professional identity and nursing: contemporary theoretical developments and future research challenges. International Nursing Review. 2012; 59(4): 562-569. doi: 10.1111/j.1466-7657.2012.01013.x

Jokinen P, Mikkonen I. Teachers' experience of teaching in a blended learning environment. Nurse Education in Practice. 2013; 13, 524-528. doi: 10.1016/j.nepr.2013.03.014

Kantar L, Alexander R. Integration of clinical judgment in the nursing curriculum: Challenges and perspectives. Journal of Nursing Education. 2012; 51(8), 444-453. doi: 10.3928/01484834-20120615-03

Kleebauer A. Funding cuts 'would put specialist training at risk'. Nursing Standard. 2016; 30(46), 9. doi: 10.7748/ns.30.46.9.s8

Knowles MS, Holton EF, Swanson RA. The adult learner: The definitive classic in adult education and human resource development. 7th ed. Elsevier: Oxford: 2011.

Longstaff $F$. The case for renewed investment in the district nursing specialist practitioner qualification. British Journal of Community Nursing. 2013; 18(9), 446-450. doi: 10.12968/bjen.2013.18.9.446

Maybin J, Charles A, Honeyman M. Understanding quality in district nursing services: Learning from patients, carers and staff. The Kings Fund: London: 2016 
Montt G. Cross-national differences in educational achievement inequality. Sociology of Education. 2011; 84(1), 49-68. doi: 10.1177/0038040710392717

National Health Service England. Delivering the forward view: NHS planning guidance 2016/17-2020/21. (2016). https://www.england.nhs.uk/wpcontent/uploads/2015/12/planning-guid-16-17-20-21.pdf (accessed 28 May 2020)

National Health Service England. NHS Long Term Plan. (2019). https://www.longtermplan.nhs.uk/ (accessed 26 ${ }^{\text {th }}$ May 2020)

National Health Service England. NHS Commissioning. (2020). https://www.england.nhs.uk/commissioning/how-commissioning-is-changing/ (accessed 30 May 2020)

Nursing and Midwifery Council. Standards for specialist education in practice. NMC: London: 2001

Nursing and Midwifery Council. Quality assurance framework for nursing and midwifery education. 2017. https://www.nmc.org.uk/globalassets/sitedocuments/edandqa/nmc-qualityassurance-framework.pdf (accessed 3 June 2020)

Nursing and Midwifery Council. Standards framework for nursing and midwifery education. 2018. https://www.nmc.org.uk/standards-for-education-and-training/standards-frameworkfor-nursing-and-midwifery-education/ (accessed 3 June 2020)

Oldman C. Advancing the profile of district nursing. Journal of Community Nursing. 2016; 29(6), 13. ISSN: 02634465

Oldman C. QNI's annual conference: Inspiring quality and success in nursing. Journal of Community Nursing. 2017; 31(1), 20-21. ISSN: 02634465

Pringle D. Expanding nurses' scope of practice. Nursing Leadership. 2009; 22(2), 1-4. PMID: 19521156 
Queens Nursing Institute. The QNI/QNIS voluntary standards for district nurse education and practice. (2015). https://www.qni.org.uk/wp-

content/uploads/2017/02/District_Nurse_Standards_WEB.pdf (accessed on 25 May 2020)

Queens Nursing Institute. The Queen's Nursing Institute strategic plan 2017-2020. 2017. https://www.qni.org.uk/wp-content/uploads/2017/01/QNI-Strategic-Plan-2017-2020.pdf (accessed 25 May 2020)

Queens Nursing Institute. Outstanding Models of District Nursing. QNI: London: 2019

Royal College of Nursing. District nursing, harnessing the potential: The RCN's UK position on district nursing. (2013).

https://www2.rcn.org.uk/_data/assets/pdf_file/0008/521198/004366_District_nursing_harne ssing_the_potential.pdf (accessed 28 May 2020)

Ruesseler M, Obertacke U. Teaching in daily clinical practice: how to teach in a clinical setting. European Journal of Trauma and Emergency Surgery. 2011; 37(3) , 313-316. doi: 10.1007/s00068-011-0088-3

Sayer L. Strategies used by experienced verses novice practice teachers to enact their role with community nurse students. Nurse Education Today. 2011;31(6), 558-563. doi: 10.1016/j.nedt.2010.10.033.

Seib C, English R, Barnard A. Teaching undergraduate students community nursing: Using action research to increase engagement and learning. Journal of Nursing Education. 2011; 50(9), 536-539. doi: 10.3928/01484834-20110531-03

Speicher T, Kehrhahn M. Analogical reasoning: A process for fostering learning transfer from the classroom to clinical practice. International Forum of Teaching and Studies. 2009; 5(2), 52-55. ISSN: $1555872 X$

Swazey JP, Anderson MS. Mentors, advisors, and role models in graduate and professional education. Association of Academic Health Centers, Washington: 1996. 
United Kingdom Central Council. Standards for specialist education and practice. UKCC: London: 1994.

Van de Mortel T, Bird J. Continuous curriculum review in a Bachelor of Nursing program: Preventing curriculum drift and improving quality. Journal of Nursing Education. 2010; 49, 592-595. doi: 10.3928/01484834-20100730-05

Yuki G. Leadership in organisations. 7th ed. Pearson Prentice Hall: London: 2010. 